\title{
Presenting A Rare Case of Duplex Left Kidney with Ectopic Insertion of Lower Moiety Ureter into Prostatic Urethra
}

\author{
Umesh H, Seetha Pramila VV*, Prashanth J, Mathew JR and Shukla AK \\ Department of Radiodiagnosis, Raja Rajeswari Medical College, India
}

"Corresponding author: Seetha Pramila VV, Professor, Department of Radiodiagnosis, Raja Rajeswari Medical College, Bengaluru, India, Tel: +91-9986377214; E-mail: varadaseetha@gmail.com

Received: September 05, 2018; Accepted: September 21, 2018; Published: September 24, 2018

\begin{abstract}
Background: Duplex collecting systems are the most common variant of renal anatomy with estimated prevalence ranging between $0.3 \%$ and $6 \%$ of the population

Casereport: We present a case of a30 years old male presenting with dull aching Pain in left lumbar region since 6 months. He was evaluated with Ultrasound (USG) abdomen and Pelvis, Micturating Cystourethrogram (MCU) and Contrast enhanced computed tomography (CECT) of Kidney, ureter, bladder (KUB) and was found to have Duplex left kidney with double ureters and ectopic insertion of the upper pole ureter into the prostatic urethra.

Discussion: USG allows exclusion of a duplex kidney and of obstruction due to a ureterocele. Renal scintigraphy is required to assess renal function, and Computed tomography (CT) may be useful on occasion in locating a small, poorly functioning dysplastic kidney. Magnetic Resonance (MR) urography has an advantage over USG and IVU in that it is capable of demonstrating ectopic extravesical ureteric insertions, thereby providing a global view of the malformation.
\end{abstract}

Conclusion: Understanding embryology, development of ureters and weight-Meyer law helps in investigating a case of double ureter. Radiological investigations may be performed in sequence depending on cases to come to diagnosis.

Keywords: Duplex kidney; Duplex collecting system; Double ureter; MR urography

\section{Casereport}

A 30 years old male patient presented to the department of urology with complaints of dull aching Pain in left lumbar region for 6 months. The pain started insidiously and gradually increased in severity and frequency to occur intermittently on daily basis. An Ultrasounogram (USG) of Abdomen and Pelvis (FIG. 1) for the above complaints and mild dilatation of left renal pelvis with duplex collecting system and ectopic insertion of ureter into prostate, Prostate parenchymal calcification was

Citation: Umesh H, Seetha Pramila VV, Prashanth J, et al. Presenting A Rare Case of Duplex Left Kidney with Ectopic Insertion of Lower Moiety Ureter into Prostatic Urethra. Clin Case Rep Open Access. 2018;1(1):107.

(C)2018 Yumed Text. 
noted. His renal function tests were within normal limits. He was referred for contrast enhanced computed tomography (CECT) kidney ureter bladder (KUB) which revealed Duplex left kidney with double ureters with ectopic insertion of the upper pole ureter into the prostatic urethra (FIG. 2,3).

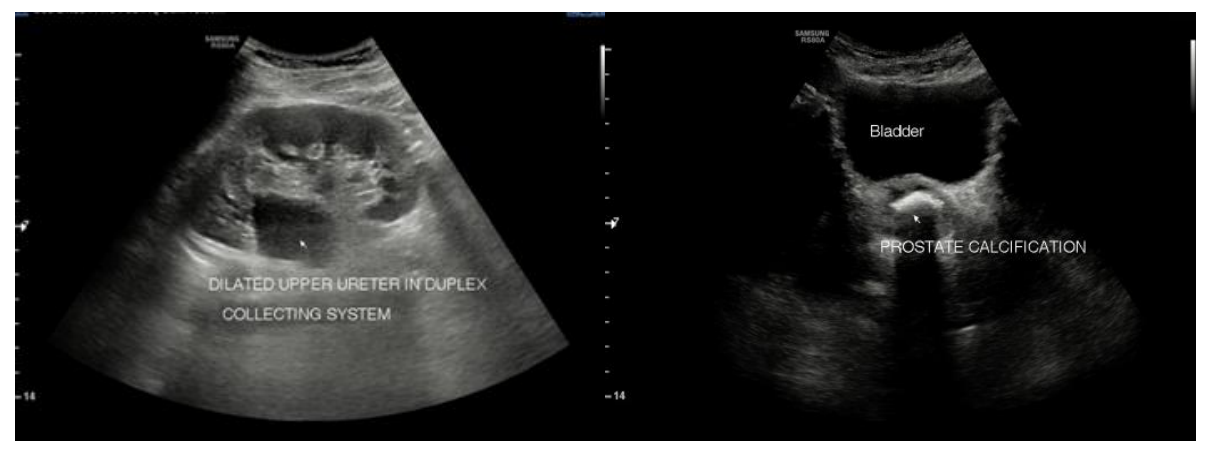

(a)

(b)

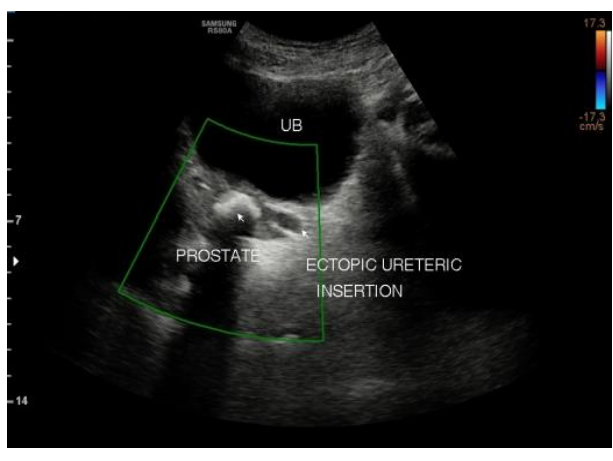

(c)

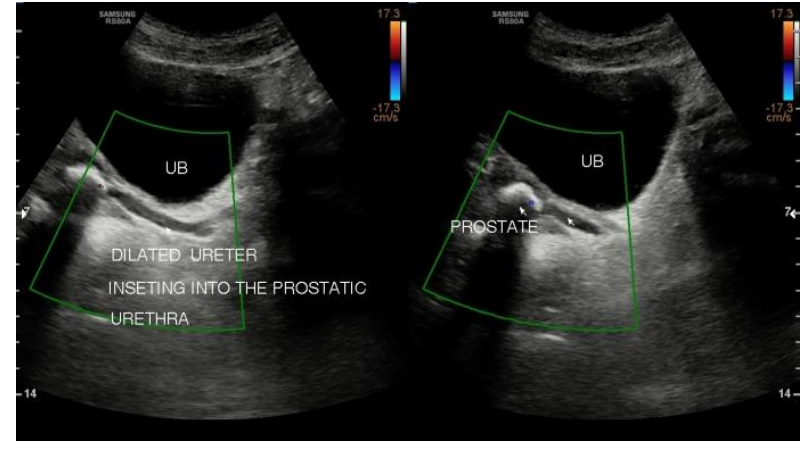

(d)

FIG. 1. a) USG in sagittal plane of left kidney dilated upper moiety collecting system and ureter. b) Coronal section USG at the level of urinary bladder showing partially distended bladder and prostatic calcification. c) and d) Coronal plane USG at the level of urinary bladder showing partially distended bladder, prostatic calcification and insertion of dilated left ureter into prostatic urethra.

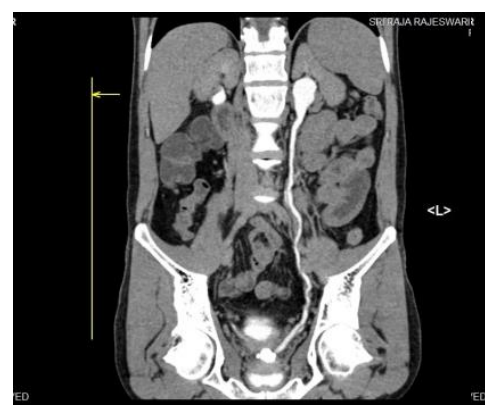

(a)

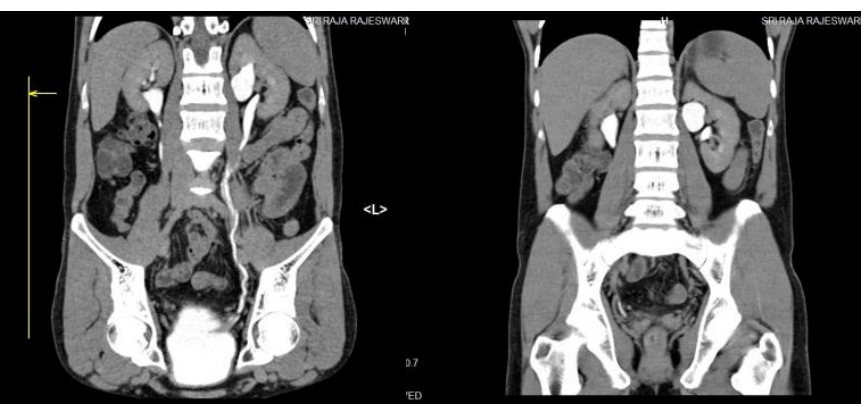

(b) (c)

FIG. 2. a) Coronal reformatted CECT showing whole length of left ureter. b) Coronal reformatted CECT showing lower pole ureter inserting into the urinary bladder. c) Coronal CECT showing duplex pelvicalyceal system in the left kidney. 


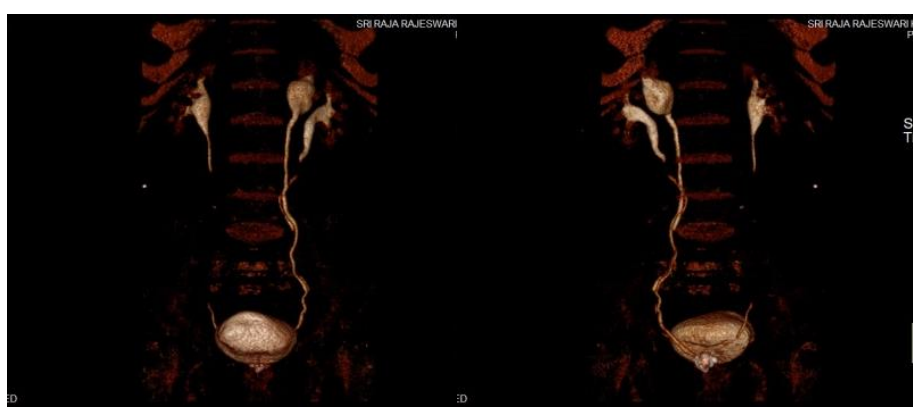

(a)

(b)

FIG. 3. a) Coronal reformatted CECT Maximum intensity projection (MIP) image showing left duplex collecting system showing lowerpole ureter inserting into the urinary bladder b) Coronal reformatted CECT MIP image is rotated to show upper pole ureter inserting into the prostate.

\section{Discussion}

Duplicated collecting systems (also known as duplex collecting systems) can be defined as renal units containing 2 pyelocaliceal systems. Duplication occurs when 2 separate ureteric buds arise from a single Wolffian duct [1].

Based on the degree of fusion, it can present as:

- bifid renal pelvis,

- $\quad$ partial ureteric duplication (Y-shaped ureter),

- $\quad$ incomplete ureteric duplication with ureters joining near or in bladder wall (V-shaped ureter), and

- $\quad$ complete ureteric duplication with separate ureteric orifice.

Duplex collecting systems are the most common variant of renal anatomy. It has a female preponderance with estimated prevalence ranging between $0.3 \%$ and $6 \%$ of the population [2]. It can beunilateral or bilateral and are associated with variety of congenital genitourinary tract abnormalities. Most patients are asymptomatic, with genitourinary tract abnormalities being detected incidentally on imaging studies performed for other reasons. Symptomatic patients usually have complete ureteric duplication in which the ureters are prone to developing obstruction, reflux, and infection.

The committee on terminology, nomenclature, and classification of the section on urology of the American academy of pediatrics suggests the use of the following terms in reference to duplex collecting systems [3]:

- Duplex kidney - The duplex kidney has a single renal parenchyma that is drained by 2 pyelocaliceal systems.

- Upper or lower pole - The poles represent one component of a duplex kidney.

- Duplex system - The kidney has 2 pyelocaliceal systems and is associated with a single ureter or with a bifid ureter (a partial duplication) or, in the case of a complete duplication, with 2 ureters (double ureters) that drain separately into the urinary bladder.

- $\quad$ Bifid system - Two pyelocaliceal systems join at the ureteropelvic junction (bifid pelvis), or 2 ureters join before draining into the urinary bladder (bifid ureters). 
www.yumedtext.com | September-2018

- Double ureters - Two ureters open separately into the renal pelvis superiorly and drain separately into the bladder or genital tract.

- Upper and lower pole ureters - Upper and lower pole ureters drain a duplex kidney's upper and lower poles, respectively.

\subsection{Embryology}

Ectopic insertion of the ureter stems from abnormal ureteral bud migration and usually results in caudal ectopia. Normally, the primitive ureteral bud travels cephalad, whereas the wolffian duct, from which it originates, travels caudal. However, if the ureteral bud fails to separate from the wolffian duct, it may be carried into a more caudal position than normal [4]. Consequently, the opening of the ureter becomes caudally ectopic. In the female, inserts into the bladder neck and urethra $(35 \%)$, vestibule (30\%), vagina (25\%) or uterus (5\%) [6]. More rarely, wolffian duct remnant such as Gartner duct or cyst [5]. In males, it empties into the bladder neck and prostatic urethra (48\%), seminal vesicle (40\%), ejaculatory duct (8\%), vas deferens $(3 \%)$ or epididymis (0.5\%) [6]. In very rare instances, it can empty into the rectum [4]. An ectopic ureter can drain a single kidney, but about $70 \%$ are associated with complete ureteral duplication.

\subsection{Weigert-Meyer law}

With duplex kidney and complete ureteral duplication, the upper renal and lower renal moiety is drained by separate ureters, each having its own ureteral orifice in the bladder. The upper renal moiety has ectopic insertion medial and inferior to the lower pole moiety ureter and frequently ends in a uereterocele.The lower renal moiety has orthotopic insertion lateral and superior to the ureter draining the upper pole and reflux typically occurs. As always, there are exceptions to the rule. Rarely reported in the literature, Stephen's ectopic pathway postulates that an ectopic ureter may drain not only distally to the normal ureteric orifice (as per Weigert-Meyer law) but may drain medially and superiorly to it (breaking Weigert-Meyer law).

\subsection{Investigations}

The classic radiologic work-up of abnormal duplex kidneys includes Ultrasound(USG), Voiding cysto urethrogram (VCUG), and Intravenous urogram (IVU). Initial screening must be performed with renal USG. At USG, a duplex collecting system is seen as two central echogenic renal sinuses with intervening, bridging renal parenchyma [7]. USG usually allows exclusion of a duplex kidney and of obstruction due to an ureterocele. It delineates the abnormal fluid-filled ureter in most cases and allows the ureter to be traced into the pelvis and into an abnormally low position beyond the bladder. Occasionally, the upper moiety may be too small to be detected, and the diagnosis may depend on recognizing the absence of an upper pole calyx or apparent excessive thickness of the renal tissue on the medial aspect of the upper pole.

The ectopic ureter and its insertion point may be visualized directly with IVU, although IVU is now performed less frequently because the dilated upper pole often shows reduced function and rarely opacifies. Renal scintigraphy is required to assess renal function, and CT may be useful on occasion in locating a small, poorly functioning dysplastic kidney. VCUG is performed to demonstrate reflux into the ectopic ureter and to identify the endpoint of the ureter. However, when an ectopic ureter drains outside the urinary system, the ectopic insertion may not be visible at VCUG. Recently, MR urography has proved capable of displaying dilated collecting systems, ectopic ureters, and ureteroceles. It has an advantage over US and 
www.yumedtext.com | September-2018

IVU in that it is capable of demonstrating ectopic extravesical ureteric insertions, thereby providing a global view of the malformation. MR urography is a promising imaging modality in selected cases.

\subsection{Magnetic resonance (MR) urography}

MR urography comprises an evolving group of techniques with the potential for allowing optimal non-invasive evaluation of many abnormalities of the urinary tract. The most common MR urographic techniques for displaying the urinary tract can be divided into two categories: static-fluid MR urography and excretory MR urography. Static-fluid MR urography makes use of heavily T2- weighted sequences to image the urinary tract as a static collection of fluid, can be repeated sequentially (cine MR urography) to better demonstrate the ureters in their entirety. Excretory MR urography is performed during the excretory phase of enhancement after the intravenous administration of gadolinium-based contrast material. Diuretic administration is an important adjunct to excretory MR urography, which can better demonstrate non dilated systems.

An eight-channel phased-array torso coil is most commonly used. It is recommended to image the abdomen and pelvis separately using the maximum number of available coil elements for each acquisition to maximise SNR and to allow highresolution breath-hold imaging. Use of parallel imaging reduces imaging time and the potential for respiratory motion artefacts.

For contrast material enhanced T1-weighted imaging of the kidneys, a 3D interpolated fat-suppressed gradient-echo sequence combined with parallel imaging suffices. Excretory phase images can be obtained approximately 5 min after contrast material injection in non-obstructed patients with normal or mildly impaired renal function. Routinely imaging of the urinary tract in the axial and coronal planes during the excretory phase is done.

\subsection{Complications}

Incomplete duplication is most often associated with ureteroureteral reflux or ureteropelvic junction obstruction of the lower pole of the kidney. Complete duplication is most often associated with (all of which are more common in girls than in boys) vesicoureteral reflux - affects the lower pole and can be outgrown, as in non-duplicated systems. Ectopic ureterocele - affects the upper pole. Produces a filling defect of variable size in the bladder. It can be identified with contrast material studies or ultrasound ectopic ureteral insertion - affects the upper pole. Ectopic ureters may function poorly, be difficult to detect, and cause enuresis in girls. Ureteropelvic junction obstruction occurs only in the lower pole and is seen in more boys than girls.

\section{Conclusion}

While investigating a case of double ureter knowledge of embryology, development of ureter and weigert-Meyer law is important. Initial screening must be performed with renal USG. VCUG is performed to demonstrate reflux into the ectopic ureter and to identify the endpoint of the ureter. MR urography is capable of demonstrating ectopic extravesical ureteric insertions, thereby providing a global view of the malformation. Demonstration of ectopic insertion of ureter can be challenging but with wide array of radiological investigative modalities that are available and with a high index of suspicion, the demonstration of renal system can be made with relative ease. 


\section{REFERENCES}

1. Ramanathan S, Kumar D, Khanna M, et al.. Multi-modality imaging review of congenital abnormalities of kidney and upper urinary tract. World J Radiol. $2016 ; 8(2): 132$.

2. Raja J, Mohareb AM, Bilori B. Recurrent urinary tract infections in an adult with a duplicated renal collecting system. Radiol Case Rep. 2016;11(4):328-31.

3. Glassberg KI, Braren V, Duckett JW, et al. Suggested terminology for duplex systems, ectopic ureters and ureteroceles. J Urol. 1984;132(6):1153-4.

4. Berrocal T, López-Pereira P, Arjonilla A, et al. Anomalies of the distal ureter, bladder, and urethra in children: embryologic, radiologic, and pathologic features. Radiographics. 2002;22(5):1139-64.

5. Fernbach SK, Feinstein KA, Spencer K, et al. Ureteral duplication and its complications. Radiographics. 1997;17(1):109-27.

6. Akdemir F, Okulu E, Kayıgil Ö. Complete Ureteral Duplication Associated with Ectopic Ureteral Orice Opening to Prostatic Urethra: A Case Report. J Urol Res. 2015;2(4): 1034.

7. Rumack CM, Levine D. The Kidney and Urinary Tract. Diagnostic Ultrasound. New York: Elsevier, USA; 2018. 